\title{
Image politics of the Arab uprisings
}

\author{
Awad, Sarah H. ; Wagoner, Brady \\ Published in: \\ The Psychology of Radical Social Change
}

DOI (link to publication from Publisher):

10.1017/9781108377461.012

Publication date:

2018

Link to publication from Aalborg University

Citation for published version (APA):

Awad, S. H., \& Wagoner, B. (2018). Image politics of the Arab uprisings. In The Psychology of Radical Social Change: From Rage to Revolution (Vol. Part III - Representations of and in Revolution , pp. 189-217).

Cambridge University Press. https://doi.org/10.1017/9781108377461.012

\section{General rights}

Copyright and moral rights for the publications made accessible in the public portal are retained by the authors and/or other copyright owners and it is a condition of accessing publications that users recognise and abide by the legal requirements associated with these rights.

- Users may download and print one copy of any publication from the public portal for the purpose of private study or research.

- You may not further distribute the material or use it for any profit-making activity or commercial gain

- You may freely distribute the URL identifying the publication in the public portal -

\section{Take down policy}

If you believe that this document breaches copyright please contact us at vbn@aub.aau.dk providing details, and we will remove access to the work immediately and investigate your claim. 
The Psychology of Radical Social Change

From Rage to Revolution

Edited by

Brady Wagoner

Aalborg University, Denmark

Fathali M. Moghaddam

Georgetown University, Washington, DC

Jaan Valsiner

Aalborg University, Denmark 
Sarah H. Awad and Brady Wagoner

Contemporary social upheavals involve the production of images by various social groups to propagate particular versions of social reality, which are in turn interpreted, challenged, rejected, accepted in part or in entirety, and used by individuals and groups on the ground. Images are tools used to create meaningful signs in the environment. Through them we act and position ourselves, and in turn they act back upon us. The Arab uprisings that commenced in 2011 across the Middle East and North Africa provide an illustrative example of these dynamics of images in revolutions. Images depicting the brutality of the authorities and the "martyrs" of the revolutions were commonplace and transmitted globally. Tahrir square in Cairo itself became a kind of visual theater, with news cameras looking down on it from the heights of buildings around the square. Thus, revolutions such as this are not only visually productive, but are in themselves visual to a great extent.

Political conflicts in today's visual culture become power struggles over presence and visibility. Authoritarian regimes assert their political dominance by controlling visual production, while the opposition seeks the right to be visually present in the city space and beyond. The right to place images in public space becomes significant beyond the meaning of the images; it becomes important also because an image in public space represents the power of the group that has placed the image and successfully defended the public space in which the image is seen. This chapter aims to unpack the politics of images by analyzing examples from revolutionary street art and government images in Egypt. The focus will be on four key functions of images in politics: to create visibility, to mobilize, to position, and to commemorate. These functions are exemplified by analyzing the transformation of urban images in four case studies: the authority figure, the flag, the tank, and bullets. The methodological framework draws on the social life of images and the social actors involved. Images have social lives that include their emergence, reception, diffusion, transformation, and destruction. By following images' continuous transformation 
in the urban space, this chapter analyzes the potential use of images for bringing about social change within shifting power dynamics.

\section{Images as Politics}

Politics involves power struggles over presence, visibility, and recognition within an established order. The politics of visual culture concerns the contestation over the representation of society and who is permitted to represent it (Ranciere, 2004). Authoritarian regimes assert their political dominance by having control over visual production and consumption, while the opposition seeks democratic representation in visible spaces; political agency constitutes possessing the ability to be seen and the right of presence and ownership of public space (Khatib, 2013). Power in that sense is in ownership over visual representation in public sphere. Images in this context are thus an integral part of the everyday politics. Consider the power images have had in representing what is happening in the Middle East today, from those driving compassion toward children in Syria's war, through those used to trigger fear of the refugees, to those produced by the so-called Islamic State Daesh propagating terror.

Likewise, visual images have constructed much of the local as well as global perception of the Arab uprisings since 2011. They have shaped what we remember of the events as well as how we remember them, such as the masses of protestors filling city squares and street art expressing their sentiment. These images communicated across language barriers, portraying events as they unfolded in such a way that people around the world could both witness these historic moments and stand in solidarity with, or in opposition to, millions of people. Images of masses in the streets and squares inspired more protestors to join the movement. This happened not only locally but also globally, for different causes that nonetheless shared the guiding idea of "power to the people." This slogan encompassed opposition to multiple systems of injustice, such as freedom from authoritarian regimes, social and economic inequality of the 1 percent versus the 99 percent, and humanitarian appeals against violence and torture.

The very act of taking to the streets makes a conflict visible (Doerr, Mattoni, and Teune, 2014), and marking a wall with political graffiti is a call for recognition and resistance to the monopoly the authority holds on public space (Awad, Wagoner, and Glaveanu, 2017; Awad, 2017). Protestors do not just proclaim space, but also produce spaces with new symbols that challenge existing representations (Lefebvre, 1991). Having a physically active presence in public spaces that people are only permitted by the state to use passively becomes a visual, political act (Bayat, 2013).

It was images that first ignited the anger and solidarity that led to the Arab uprisings. From early 2011, images of Mohamed Bouazizi from Tunisia, Khaled Said from Egypt, and Hamza al-Khatib from Syria were catalysts for local movements as well as global attention as they became symbols of state injustice. Bouazizi set himself on fire in protest of police harassment and humiliation, while Said was beaten to death in broad daylight by police for exposing corruption (more on this below), and alKhatib was killed under torture by security forces after he wrote "the people demand the fall of the regime" (a common phrase during the uprisings) on a public wall. Their images transformed police violence from a state-controlled act into visual evidence in the hands of protestors (Khatib, 2013).

In modern media-saturated societies, images become a field of knowledge in their own right. The production, circulation, and interpretation of images are part of the collective elaboration of meaning and thus intrinsically political (Rogoff, 1998). Revolution street art and graffiti in the Middle East created influential images of the Arab uprisings. Activists' use of these aesthetic means of protest, transformed art from being class-based capital tied to amusement and wealth (Bourdieu, 1984), to a tool of resistance alongside gas masks in the midst of protests and clashes. The messages communicated on the wall were used to assert a counternarrative of events, mobilize and unite people around revolutionary goals, reconstruct representations of the authority figures challenging their power, and socially document and remember events as were seen and felt in the street (Awad, 2017; Awad and Wagoner, 2015; Awad, Wagoner, and Glaveneau, 2017). Images from the Arab uprisings are of protestors taking ownership of representing themselves and constructing a social reality to present to the world, as well as responding to other actors' narratives.

Revolution can thus be seen as a dramatized performance using powerful symbols to win over audiences that are both national and international. The first day of protest during the 2011 Egyptian revolution was carefully choreographed to take place on "national police day," which commemorated how the police stood up to the British occupation. In so doing, it put in stark relief the arbitrary and brutal police of contemporary Egypt that would attempt to squash the protest with the heroic role they played in the past. The strategy of the protest was to meet at peripheral spaces of the city - thereby dividing police attention and moving toward the central point of the city, Tahrir square (which 
appropriately means "liberation" in Arabic). Tahrir square was of key importance precisely because of its visibility. During the protests that followed over the eighteen days until Mubarak was removed and beyond, Tahrir became a kind of political theater in which the revolutionaries could effectively spread various images of the government's attempts to break up the movement. These were taken by cellular phones and increasingly by news channels perched in the buildings surrounding the square. Standing in the middle of the square one could see innumerable cameras looking down. News channels the protestors disagreed with got an endless barrage of laser pointers directed up at them to break their image, as part of the protest.

\section{Visual Culture: Thinking through Images}

Images create affective symbols as they circulate, embodying multiple meanings. A symbol is a sign which carries multiple meanings and significance: one meaning is indicated being the obvious "face value" of the symbol (i.e., what it denotes), and another is the "hidden value" (i.e., its connotations) which produces a largely affective response without being definitely or purposively attended to (Bartlett, 1924; Wagoner, 2017). For example, the image of Khalid Said's mutilated face after he was beaten by police in Egypt took on the hidden value of fighting police corruption and injustice more generally. It became a rally point around which a group could organize itself and expand its membership. Police brutality was nothing new, but was normally directed at the poor and was now made visible. Said's case was special in that he was from the middle class and was killed in front of others in broad daylight. Thus, he could more easily serve as a symbol uniting all Egyptians against the police.

The image of Khaled Said as well as many other revolution images traveled to different contexts creating symbols of solidarity among different countries. Figure 11.1 shows the portrait of Khaled Said painted on a fragment of the historical Berlin Wall, symbolically merging two separate contexts of struggle together, as part of the Freedom Park Project. The photo was painted by Andreas von Chrzanowski (Case), and the Arabic calligraphy at the bottom was written by Mohamed Gaber (Gue3bara), reading "We are all Khaled Said," which was the name of the Facebook page made in his honor and used to call for and organize the protests of January 25, 2011. The image of Said's mutilated face fulfills the four functions of images we highlight, namely, to create visibility, mobilize, position, and commemorate. We will briefly outline each function here

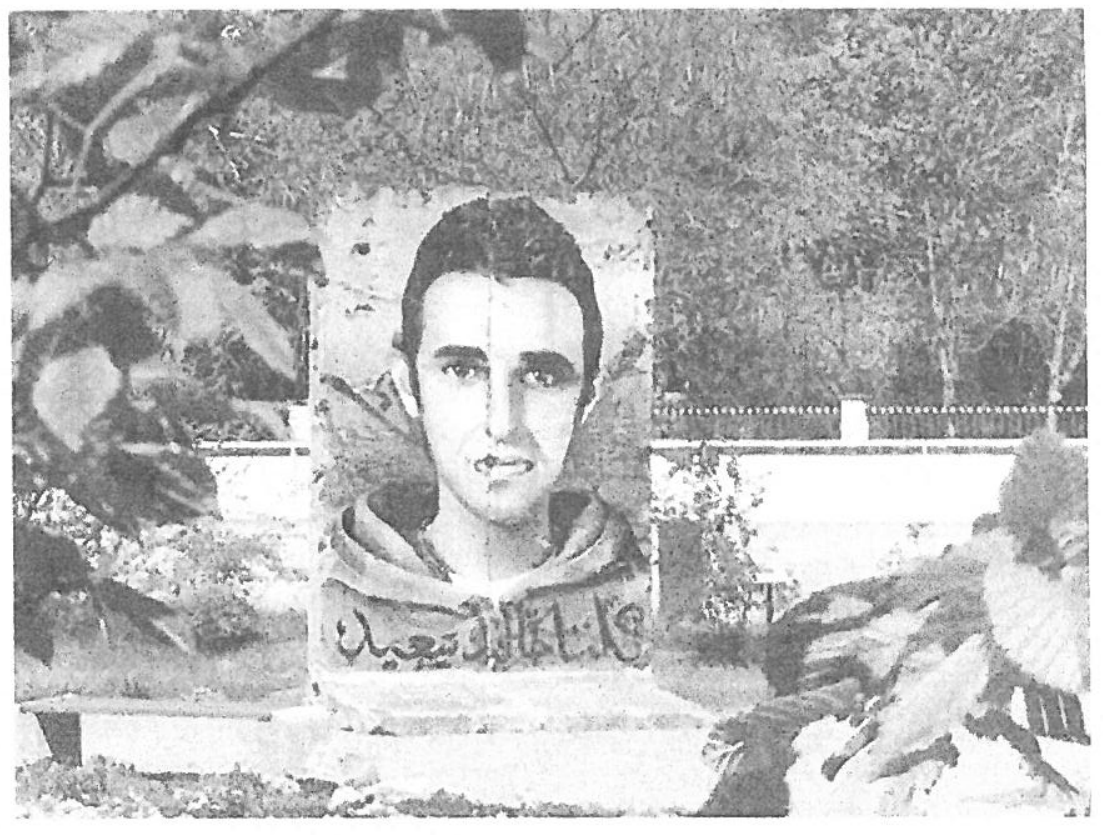

Figure 11.1 Khaled Said's image on a piece of the Berlin Wall Photo credit: First Author, Berlin, April 2017

in turn and later further elaborate them in relation to case studies of different kinds of images created during the Arab uprisings.

\section{Create Visibility}

To represent in politics means to stand in for a group of people in negotiations with other groups (i.e., as a representative), while in psychology its meaning concerns a symbolic depiction of some object. The two meanings of "represent" convergence in the politics of images. For example, images of Khaled Said represents the concrete person killed by police on the one hand, but also the revolutionaries and their demands for "life, freedom and social justice." This public representation of an image can bring visibility to a social movement's cause. Whether a photo or a piece of art, images are communicative devices that make visible to an object, a subject, or an idea, and the group that produced it. Images are different from text in the immediacy by which they make absent objects present, their capacity to make abstract entities concrete, and to create fictional characters that embody generalizations and stereotypes (Lonchuk and Rosa, 2011). Moscovici (1984) has argued that they give 
a "figurative nuclei" to social representations, working to naturalize our everyday knowledge and give shared reference points for a group to communicate and organize itself.

Images borrow from currents of ideas and values already existing within a society, but can also negotiate them, reconstruct them and create new ones. This power to represent and make visible gives images the capacity to produce spaces that embody the group who made them. Who is allowed, and what is allowed, to be visible creates spaces of power, inclusion, and exclusion. Images tell us something about where we are, hint at the power dynamics, and make us feel foreign or at home (Lonchuk and Rosa, 2011). Misrepresented groups often strive with the use of images to create visibility, proclaim city space, and create an atmosphere of solidarity to re-affirm their denied recognition. Regimes, especially authoritarian ones, monopolize visual culture in order to control how society is represented. This is done by producing images that communicate power and indicate who belongs and who does not.

\section{Mobilize: Shaping Emotions and Motivating Action}

Two modes of thought that govern human psychology are conceptual reason and ideational images. While the former creates a more distant and evidence-based relation to reality, the latter is vivid, emotional and directly suggests action (like an idea implanted by a hypnotist) (see also Wagoner, Chapter 5). Le Bon (1895/2002) argued that the statesmen should govern the masses by appealing to the latter mode of thought through evoking powerful images, rather than by providing them with reasoned arguments. Although we can criticize his one-sided view of the public, he was clearly on to something with regards to the power of images to move masses. Thus, beyond representation and recognition an image can easily be embodied as an affective symbol that mobilizes us to actions by appealing to our emotions. The perceiver of an image may be moved to engagement and self-transformation by appropriating a powerful image in a work of art (Dewey, 1934/2005), or to collective action through various symbols expressing outrage, and calling us to action.

The power of the image over the human mind resides in its silence, impassiveness, and insistence on repeating the same message, in its capacity for absorbing human emotions and projecting them back as a demand for reflection (Mitchell, 2005). In revolutions, images ignite emotions and rally people in the streets. As already mentioned, it was images of Mohamed Bouazizi in Tunisia and Khaled Said in Egypt that sparked revolutions in each country. In the immediate aftermath of Mubarak's being pushed out of the presidency, cities of Egypt were filled with empowerment and solidarity street art, including national flags, fists clenched in the air and the Christian cross and Islamic crescent placed together. Moreover, through circulation of images on television and the Internet, mobilization transcended geographic distance to spread revolutionary euphoria from one country to another.

\section{Position}

Images also function as condensed symbols that make arguments vis-àvis other alternative positions within a society. Through these arguments people position themselves and others in relation to different social issues, ascribing various rights and duties to different social actors (Harré and Langenhove, 1998). The actors are also positioned as upholding or violating those rights and duties. In the online page calling for the Egyptian uprising, the photo of Khaled Said was placed beside his mutilated face after the attack, with the slogan "we are all Khaled Said." His young familiar look and the slogan explicitly positioned the perceiver as sharing the vulnerability to the police's arbitrary aggression. The visual expressed outrage at the violation of people's rights to justice and safety, and the duty to stand in solidarity against the injustice. Furthermore, it positioned the authority as having failed in its duty to protect its people.

In this context, the putting forward of arguments takes the form of a dialogue between social actors. As will be illustrated in the "tank" example further below, an effective visual image not only asserts the producer's argument, but also provokes its audience to position themselves within the argument. It creates both attention and tension, posing a challenge to the viewer. If the image is too familiar the viewer will only see it as a cliché, and if it is too unfamiliar the viewer will reject it outright. To create perceptual, emotional, and representational tension for the viewer the image needs to balance between the known and unknown, old and new. It involves representing the existing social reality, while simultaneously communicating something new that violates that reality (Marková, 2003). Thus, by following images as they respond to one another we can track how different positions evolve within an ongoing social dialogue.

\section{Commemorate}

Images also simplify events into symbolic icons that become part of our collective memory, as has happened with Khalid Said's image becoming an iconic visual to commemorate the injustice leading to 2011 uprising in Egypt. Our spatial framework is filled with images that trigger selective events of the past and certain ways of remembering them. Those 
images become symbolic actors on the historical stage; feeding into the stories we tell ourselves (Mitchell, 1984) and representing the affective relationship a community has with its past (Halbwachs, 1950). Images of the past are continuously reproduced and reconstructed to feed into the demands of the present and the desired future of different social actors. These images can then be used as analogies to understand a host of current events and concerns. As the psychologist Frederic Bartlett (1932, p. 219) explained, "by the aid of the image... a man can take out of its setting something that happened a year ago, reinstate it with much if not all of its individuality unimpaired, combine it with something that happened yesterday, and use them both to help him to solve a problem with which he is confronted to-day." In this account, there is a dynamic relationship between past and present; the past is used to serve current needs and is reconstructed on that basis. Thus those having the power of image production and circulation have the power over stabilizing certain narratives of the past, thereby shaping the imagined future. Power determines which aspects of the past are circulated as visual representations (Rogoff, 1998).

\section{Studying the Transformative Nature of Images}

To research these different functions of images, we need to not only look at the production and perception of image, but also at the process the image goes through in the public sphere, its social life. Images are not static objects finding a place in a single context; they have social lives that include how they are produced, received, diffused, transformed, and destroyed. By following the images' continuous reconstruction, we high light processes of dialogue between different social actors and concomitant social changes in society. Following image's transformation is also informative as to the intertwining of different public and private spheres, as well as the online and physical spaces through which an image travels. Many of the protest images were carried from squares to news and online media, while images and caricatures from social media where used in revolution graffiti and street art. This highlights the enduring power of images that travel, comment on each other, and continuously respond to the dialogues ongoing in society. Images are also understood as situated within particular sociocultural contexts through association with a complex stock of cultural knowledge and identifications, which affects how they are interpreted and re-appropriated by different social actors (Mitchell, 1994).

Images as tools for social and political action, involve different social actors, who take up the different roles of image producer, receiver, transformer, and destroyer, depending on the context (Awad, Wagoner, and Glaveneau, 2017). For example, during the uprising every protestor in a sense was an image producer, broadcasting to a local and global audience through social media. Also, a revolution mural in the street has the artist as its producer, and pedestrians and the government as its audience and potential censors. While for a political campaign poster the producer could be the authority for which pedestrians are the audience. The audience in each case could change the image, reproduce it, transfer it to another medium, or destroy it. The destruction or censorship of images is indicative of the political atmosphere and what is tolerated by the government or the general public. Revolution graffiti in Egypt was not only whitewashed by local government officials but also often sprayed over or scratched out by pedestrians who disagreed with the content displayed in what they identified as "their" neighborhood area. Government censorship is different, however, in that it not only destroys images in the streets and censors their reproduction, but also goes after image producers and circulators through arrest and issuing laws criminalizing their actions (Awad, 2017).

This framework offers one way of looking at image politics, analyzing: How do images emerge through actors' production efforts? How are they received according to each social actor's position and background? How then are images diffused and circulated within a context? What transformations do they go through in this process? Why do some images gain visibility and go viral while others have shorter life spans? What images catch people's attention?

Having highlighted our focus of the four functions and the methodological focus on the transformative process of images, we illustrate the above with four case examples, each representing one of the functions mentioned above: the authority figure, the flag, the tank, and the bullets. The data presented below builds on a more elaborate ethnographic data set collected from Egypt over the period from 2014 to 2017 that includes; interviews with street artists and pedestrians, city walks, photo documentation and visual analysis, as well as archived material from news and social media (see Awad, Wagoner, and Glaveanu, 2017; Awad, 2017)

The Authority Figure: Images as They Create Visibility and Produce Spaces

Images of authority, especially in authoritarian regimes who have monopoly over the visual culture, create spaces with homogenous clear messages about power. In these contexts, as Foucault (1977) points out, 
the citizen is continuously the object of the gaze of the state, whether physically through surveillance, or symbolically through the watchful eye of the leader's image in public and private space. Here the image of the authority figure represents not only his person and leadership but also the state and what it stands for. Through the distribution and circulation of those images in city space they create strong visibility, displaying power and control. It is not surprising that the visible presence of the ruler, whether king, emperor or statesmen, has been a common motif throughout world history.

In the Middle East, the face of the president or king is a prominent feature in public space (in many homes as well, the intrusion of the state is such that people feel obliged to show images of the leader). This personification of politics is common because it is easier to understand a man than a political program; leaders take on the role of associating politics with their personas, displaying charismatic nationalistic attributes that appeal to their supporters (Khatib, 2013). Producers of such images are normally governmental institutions, placing the image of the leader in numerous strategic spots beginning from primary school classes in public schools socializing young citizen early on to the "father" of the nation. The role of production is not only top down however; the authority image's social life extends to being reproduced and circulated by "loyal" citizens, displaying them in their businesses and homes. It is an act of support and alliance but also in many cases protection from the system. Khatib (2013) further explains that people post authority's images not because they love them, but because the system is self-enforcing and people are accustomed to it; they have internalized its control.

Of interest here is the transformation this image underwent during the political unrest and the alternative spaces that were created. During the uprisings, the image of authority could be seen as what Mitchell (1986) refers to as a site of special power that must be destroyed or exploited to reverse its idolism. The "divine" attributes of the authority images were contested and destroyed to bring about the questioning of their power and the possibility of toppling their regimes. This could be seen during protests in caricature images of leaders mocking them and revolution street art visually putting the power of those leaders in confrontation with the power of the people. The divine image was further reversed by media images after regime change and the removal of those leaders. One clear example is that of the violent killing of Qaddafi in Libya: media images of his corpse transformed him from a superior being into a nonhuman object in the hands of his killers (Khatib, 2013). Also in Egypt, one widely circulated media image representing the victory of the uprising was a picture of children in a public school taking down the oversized image of Mubarak from their classroom. By this destruction of the authority's physical and representative body, the revolution thereby denaturalizes the existing social order.

In his over thirty years as Egypt's president, Mubarak created an image of himself as a war hero, a leader of the Arab world, and promoter of Egypt's economic development. Anything that contradicted this image was censored to keep a coherent public discourse. The limited space that was left for "freedom of expression" targeted other government officials and ministers, while keeping Mubarak and his family out of any public ridicule. In the Middle East Peace Talks in 2010, a news image of Barak Obama in the lead, following him Binyamin Netanyahu, Mahmoud Abbas, Mubrark, and King Abdullah II slightly behind was taken of the event. The next morning state run newspaper Al-Ahram published the photo after editing it to place Mubarak at the forefront of those key figures. Interestingly this decision to alter the photo did not seem to come from the president office but rather the newspaper editorial staff. The editor-in-chief defended the image by saying it was a metaphoric edit, only meant to illustrate Egypt's leading role in the peace process (Guardian, 2010). This again reflects an internalized understanding of the visual discourse, what can be represented and how, when the real image did not match the conventional representation of the president, it was altered, so as to fit the image people should be seeing.

Revolution street art created a public field visibility through which this divine status was contested and debated, not only for Mubarak but also for the leaders who followed him: Tantawi, Morsi, and El Sisi. The same function of image as a tool for representation and creating visibility was used to reconstruct the visual representation of power. Several street art paintings were about flipping the powerful traditional portrayal of Mubarak, to represent him as weak and scared in front of the power of the people. Irony was also a common tool in graffiti and street art images. Artists appropriated the traditional divine portrayal of authority, and re-represented it with a twist to bring about an opposite meaning, thus potentially triggering reflexivity in viewers (see also Wagoner, Awad, and Bresco, forthcoming). These images did not only mock the leaders but also those who glorify them. Figure 11.2 uses traditional imagery of holding high the glorified framed image of the leader. But by changing the face of the leader and the follower to chimpanzees, it represents the blind and irrational devotion of followers for their simple-minded leader.

The transformation of the leader's image into graffiti images ridiculing him, represents a visual reversal in public space. Even though these practices were there before the revolution, they were in what Scott (1990) 


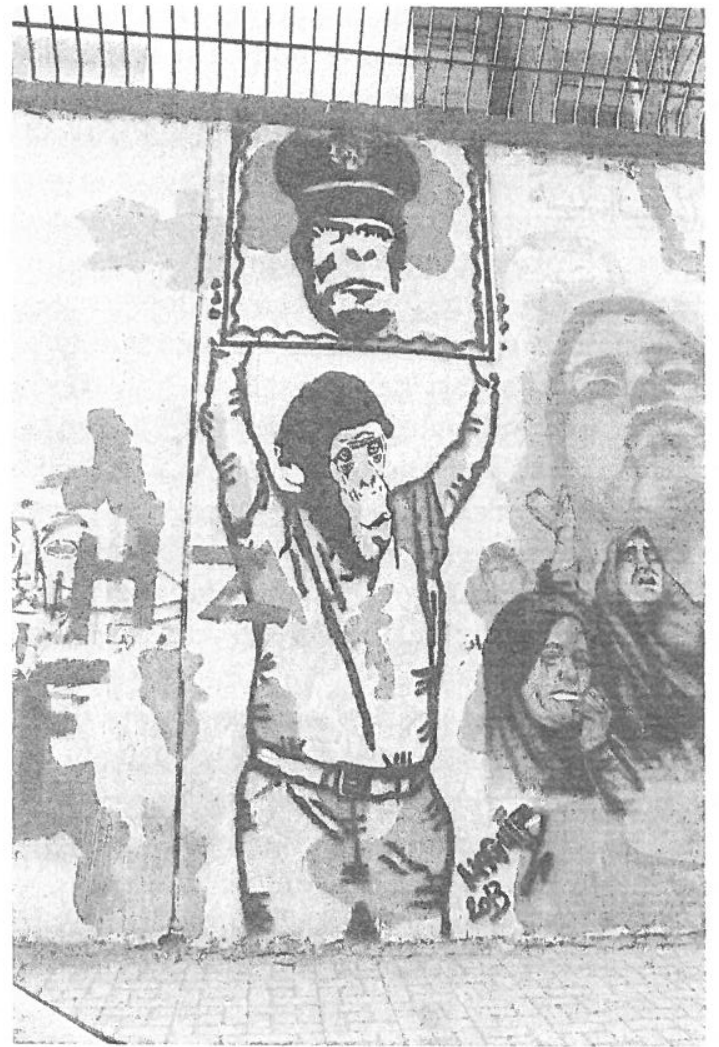

Figure 11.2 Painting by artist Naguib at Tahrir Square, September 2014

Photo credit: First Author

terms, offstage hidden transcripts, where the hegemonic visual representation of authority is only mocked and degraded in private social gatherings and online media. The revolution provided a space for those hidden transcripts and backstage performances to be spoken directly and publicly in the face of power. This created new spaces with reconfigured boundaries of what could, and could not, be said in urban space.

This revolutionized urban space was not long lived. Since El Sisi took office in 2014, there has been a tightening security grip on such forms of expression. This censorship not only applies to graffiti images, but also to images produced on social media. Because images on social media are harder to control, authorities often go after the image producers. In 2015, Amr, a twenty-two-year-old serving his compulsory military year, was sentenced by military court to three years in prison for creating a picture of El Sisi with huge black Mickey Mouse ears and sharing it on Facebook. The prosecutors used screenshots from social media as evidence, arguing Amr posted a series of disrespectful images of the president that violate the expected moral behavior and push the boundaries beyond acceptability (Farid, 2015). This example, explicitly expresses authority's tight "moral" control over visual representation. In spite of these examples of ironic reversal, or perhaps because of them, the glorification of Sisi in images still persists. El Sisi is often portrayed with angle wings or a superman suit by his supporters in the street, in newspapers, and online. Those images reinforce the image of El Sisi as a national hero and savior of Egypt, such that those who suggest otherwise are labeled as enemies of the nation. These glorifying images however continue to trigger further ironic counterimages by the opposition.

\section{The Flag: Images as They Shape Emotions and Mobilize}

The famous images igniting the different Arab uprisings mentioned in the introduction are clear illustrations of how certain images move us beyond mere recognition, to affective reactions and in many cases mobilize action. We will discuss here an example of how even the most diffused and banal images can start a new social life following major events to mobilize people toward certain feelings, affiliations, and actions. National flags take up a novel symbolic meaning in times of turbulence. As powerful symbols of national identity they can be used to mobilize collective action toward a common goal. In moments of revolutions, triggered by the disruption of routines, people psychologically invest significant emotional energy into the symbols of nationhood (Giddens, 1985). It is thus not surprising that during and immediately after the eighteen days of the 2011 Egyptian Revolution that flags were being painted and waived all over the country. However, four years later the same flag would take on an opposite meaning.

Unlike the common use of the Lebanese flag after the civil war as a symbol of unity, the Egyptian flag was not a common daily object to be displayed and flagged. It was only apparent around football matches and on poles in government offices and schools. Protest in the years prior to the uprising in 2011 mostly used signs with their demands, without evoking a visual of the flag.

In 2011, an image of a protestor climbing up to a light pole and waving the Egyptian flag in Tahrir square with the background of thousands of protestors became a powerful symbolic image of the 
uprising: It connoted the slogans "power to the people" and solidarity under one national cause of "bread, freedom, and social justice." A group of protestors walking through neighborhood streets waving the flag and calling on people to join was a common practice during the eleven days of protest in 2011 before Mubarak's removal. In contrast, pro-Mubarak protest groups could easily be identified by the large portrait images of him that they carried. At this time, hanging the flag from a residential balcony was a sign of support for the revolution. Moreover, many of the revolution graffiti images used the Egyptian flag as a symbol of national unity and empowerment.

Fast forward to 2014 after military takeover and president El Sisi getting into power. At this time, a flagpole was erected in the center of Tahrir square (Figure 11.3b) after dispute over what memorial can represent the revolution (see Awad, 2017). However, this time the flag was met with much skepticism from activists, who saw it as backstabbing those who lost their lives in the square during protests and an appropriation of the protest square by the new government. The flagpole was referred to as a "khazou," roughly translated as "an impalement." In a previous study, when participants were shown images of the flag on a billboard with the statement "in the love of Egypt," they all readily identified it as a pro-military government image (see Awad, 2017). Also waving the flag in the street or hanging it from ones balcony now had the opposite meaning of supporting military rule.

How did a symbol, so common and culturally diffused, come to be appropriated to mobilize for such opposite causes in such a short time? How did the government monopolize the image of the flag right after the revolution, such that it became an automatic identifier of the regime instead of a revolutionary symbol?

The military backed government after the revolution quickly reaffirmed full control of the representation of the nation using collectively held symbols such as the flag and generic statements that define nationalism and love of one's country. After the military takeover, the image of the flag was quickly appropriated to mean counterrevolution. Hanging the flag was used to proclaim space for the authorities rather than the people. The military also heavily used it in a visual campaign to act in patriotic solidarity with the government against terrorism. The flag became the symbol of the army's dedication to the people in what the campaign refers to as two revolutions, first against Mubarak in 2011, and second against Muslim Brotherhood president Morsi. The appropriation of the flag was the visual part of the nationalistic discourse widely communicated in official media and city space after the revolution: to be a loyal Egyptian patriot is to support government, opposition is about

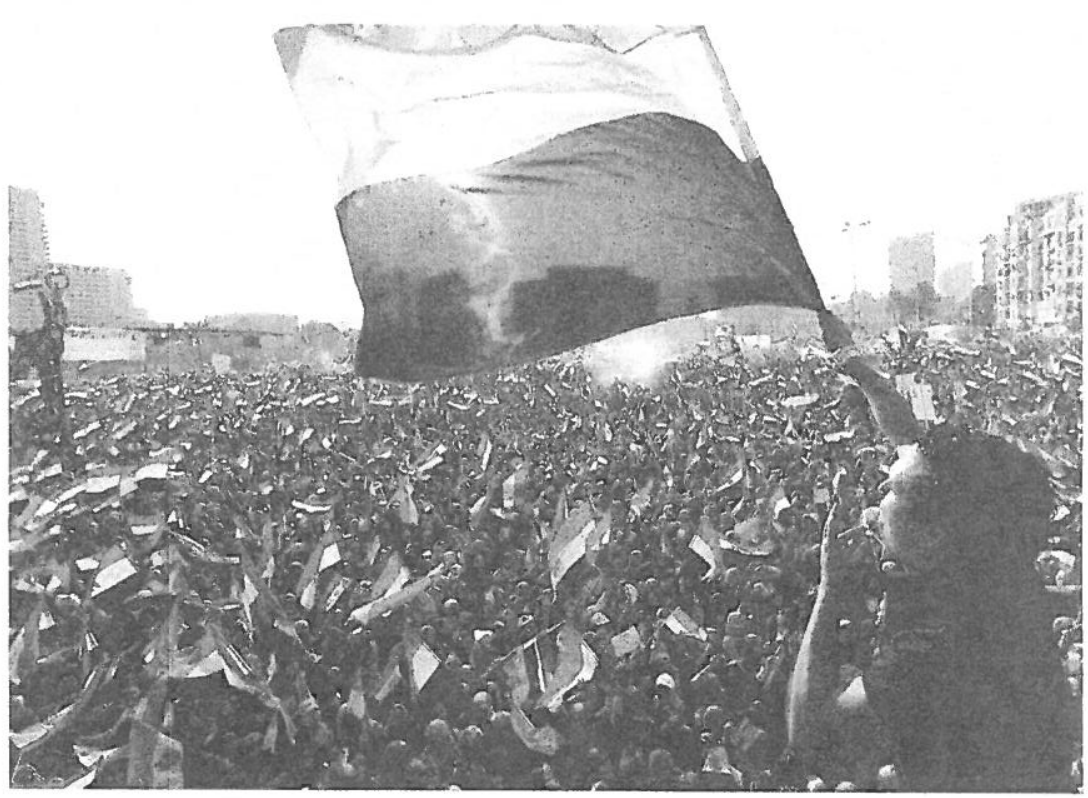

(a)

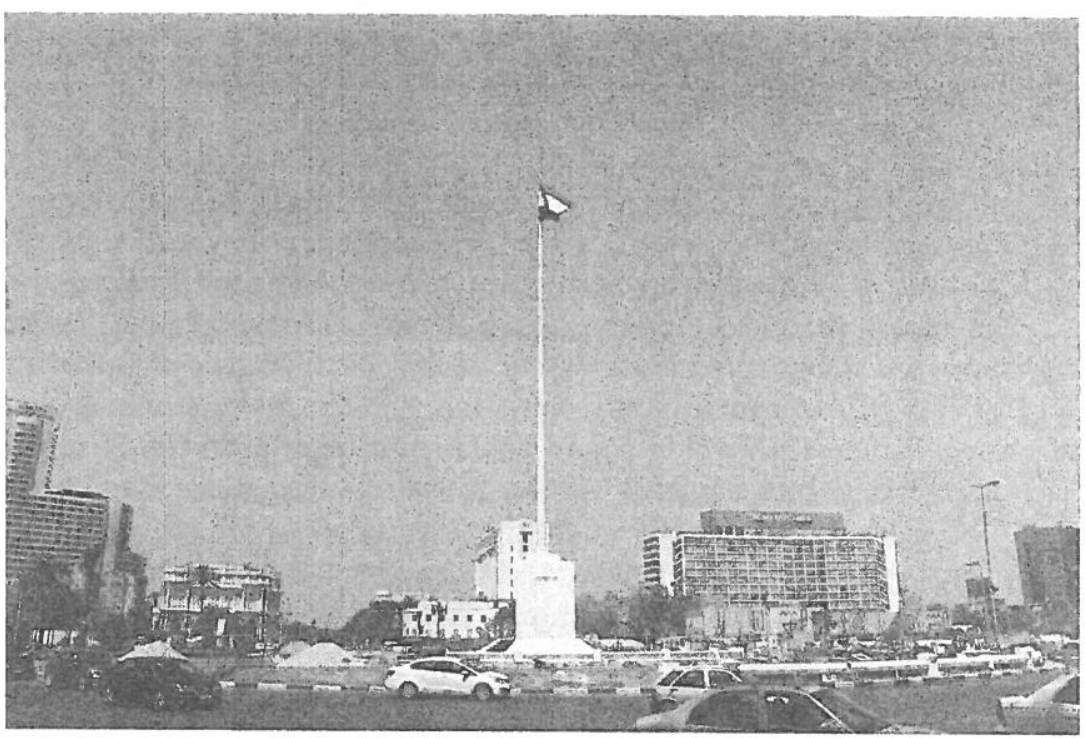

(b)

Figure 11.3 Tahrir Square (a) after Mubarak steps down in 2011 and (b) in May 2015

Photo credit: (a) Mohamed Abdel-Ghany and (b) First author 
being a traitor to the country in a time of instability and its fight for safety against terrorism.

In this example, the flag's use goes beyond its pragmatic communicative message to being a signal of spatial borders and affiliations. It performs a further symbolic function of being a "condensation symbol" and "a focus for sentiment about society" (Firth, 1973, p. 356). Flags symbolize the character of a nation, and this character varies by who is waving it, where, and how. Flags come to take those meanings from their poles standing in the street, from being waved by a loyal citizen or a protestor, or from being waved in a football match. In those instances, it carries more of an affective rather than an informational message. The numerous flags we see today are un-saluted, un-waved, and unnoticed. They are banal daily reminders of nationhood, being neither consciously remembered nor forgotten (Billig, 1995). The flag becomes embodied by meanings now prescribed to it by the new authority, erasing its earlier meaning. It is only the flags now being waved or saluted that ought to be noticed.

The same flag still frequently appears in the daily life, saluted by children in school every morning, waved at football matches, and standing tall on government flagpoles. However, following its social life over the last few years in Egypt illustrates shifts in power and how the meaning of patriotism has changed, from being a protestor to a citizen loyally following his/her duty to the authority.

\section{The Tank: Images as They Position}

While images represent, create spaces and mobilize, they subsequently pose arguments for a certain position, displaying the producer's stance on a contentious topic. For example, images of different protests in the uprisings positioned protestors as either freedom fighters or terrorists and foreign agents causing civil wars. The choice of which images got coverage in the media, what photo angle is taken of a protest, and the content of each image posed an argument for or against the protest action. Similarly, photos of Syrian refugees and their circulation in European media make an argument for their helplessness or present them as a potential threat to European culture and security.

An illustrative example of this argumentative function of images is in the layers of graffiti on one wall beneath 6 October Bridge, at Zamalek in Cairo from 2011 to 2013. This example also highlights the social life of images methodology mentioned above, and the analytical value of following the transformation of one image through different actors. The continuous line of argument in this image's social life concerns the contentious military role in the revolution, symbolized by the tank. Was the military a savior of the 2011 revolution or did they take advantage of the situation for their own gain? Does the tank symbolize protection or brutality? This question remains in people's minds, especially given the current military backed regime ruling Egypt.

The visual dialogue started with a street art image drawn by artist Ganzeer and his friends in May 2011 (Figure 11.4a). The image shows a tank facing a young man on a bicycle carrying a breadbasket. The boy serves as a representative of the working class, which revolution aimed to protect with the demands for "bread, freedom and social justice." It is also noteworthy that the word for "bread" (aish) in Arabic also means "life." Immediately we are struck by the disproportionate power of the two actors. Moreover, the positioning of the tank face-to-face with the boy and his bicycle subtly makes the argument that the army, who at that moment is supported by many Egyptians and seen as protector, could at any moment turn its weaponry against them.

Soon after in October 2011 tanks did turn against civilians in a violent crackdown on a protest in an event known as the Maspero Massacre. During the event tanks intentionally ran over protestors killing dozens. This was the first transparent sign that the military's self-proclaimed role as protectors was problematic. In January 2012, another artist, Mohammed Khaled, transformed the tank and bicycle image to document the massacre, painting civilians falling under the moving tank with a pool of blood underneath them (Figure 11.4b). Around the bread seller, protestors were added holding "vandetta" masks, an international symbol of resistance. The argument is clear: the military are killers and citizens have the duty to protest against the violations of their rights.

Actors from an opposing position quickly countered this argument. Ten days later, a pro-army group called "Badr Battalion" erased most of the new additions to the image (Figure 11.4c). The tank now stands idly besides protestors with the slogans "the army and the people are one hand" and "Egypt for the Egyptians." The latter is a slogan from 1880 s that was used for pro-nationalist anticolonial campaigns and was later appropriated by the military when they seized power in 1952 . The protestors are now transformed into patriotic civilians cheering for the tank with flags in hand instead of the vendetta masks. The image makes the argument that citizens should be patriotic by supporting the military which will lead to social stability. As described above, the meaning of the flag is already changing to signal this support.

In response to this, a street art group named "Mona Lisa Battalion" erased what the pro-army group had done and drew different motifs in front of the tank, including a sketch of military leader Tantawi's face as 


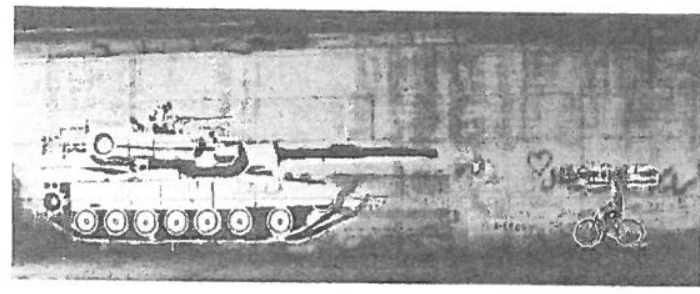

(a)

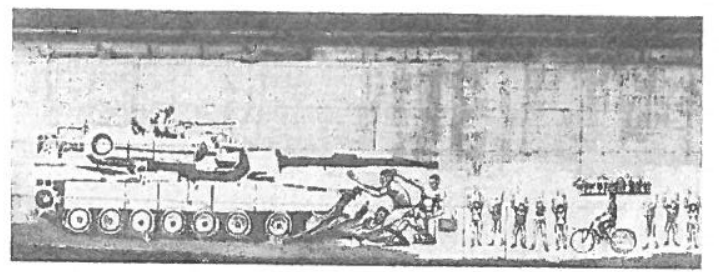

(b)

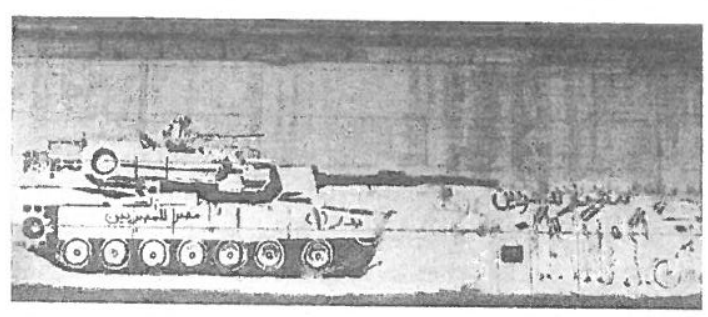

(c)

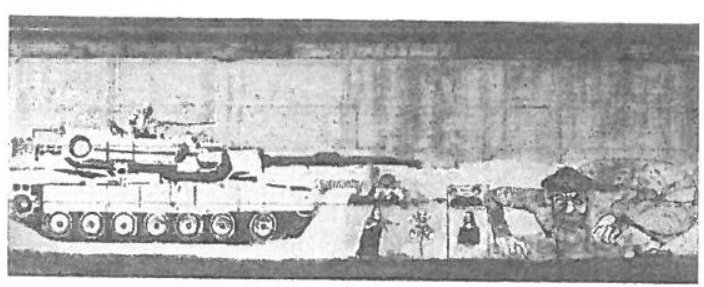

(d)

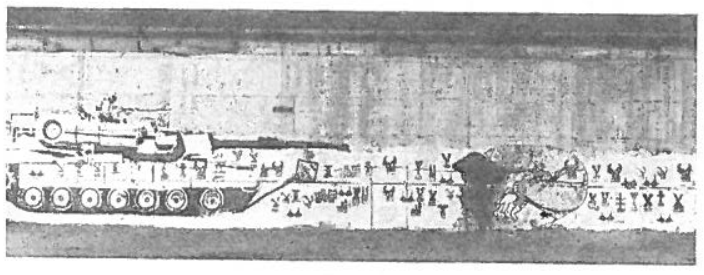

(e)

Figure 11.4 Transformations of the "tank and bicycle" mural from 2011 to 2013

Photo credit: (a,d) Suzee in the City (suzeeinthecity.wordpress.com), $(b, c)$ Mia Grondahl and (e) Bahia Shehab petals of a flower faced with a famous Egyptian actress holding a rifle against it (Figure 11.4d). Also to the right artist Mohamed Khaled drew a green army monster devouring a protestor with blood pouring out of its mouth.

The authorities responded by white washing the wall, leaving only the tank, and using black paint to erase the army monster. Yet again, a new coat of paint was added by artist Bahia Shehab; using her calligraphy project $A$ Thousand Times No, she stencil sprays the wall with different Arabic calligraphy styles of the word "no." Underneath each "no" is a different message, such as "No to dictators," "No to military rule," and "No to violence." Shehab has created a series of graffiti images using different Arabic calligraphy styles of the word "no" and used them to spray paint a series of quotes objecting Egyptian authorities in streets of Cairo (see www.ted.com/talks/bahia_shehab_a_thousand_times_no).

Similar to other revolution street art, the wall was completely whitewashed in June 2013 by local authorities. The image, its layers of reproductions, and its final erasing tell a story of contention political argumentation. Each transformation of the image positioned the actor from the symbol of the tank, as well as their position from the previous argument, and with minor changes to the paintings transformed the message several times to opposite meanings.

\section{The Bullets: Images as They Commemorate and Document}

Commemorating and documenting the killing of civilian lives through the traces of bullets has been a common practice in the aftermath of collectively felt violence and has become part of contemporary war tourism. In Lebanon, nearly three decades after the civil war, the few remaining buildings and ruins by the Green Line in Beirut - the line that divided the city in two during the war - are still covered in bullets. In the absence of a war memorial, their walls become the primary places of memory for the war. Today there are different attempts at preserving them in the form of official memorials of the conflict (see Fordham, 2017). More recently, bulleted walls and ruins in Iraq and Syria continue to tell a story of the wars ongoing there. In many instances, those walls are used as a canvas for street art interventions adding stories of defiance and hope to the imprints of violence.

In Egypt, the remembrance of the lost lives in the 2011 uprising was one of the main themes of revolution street art. Many revolution murals commemorated the revolution "martyrs" using two visual memory functions: honoring the victim and documenting the injustice. The first commemorates and pays respect to the deceased through drawing 


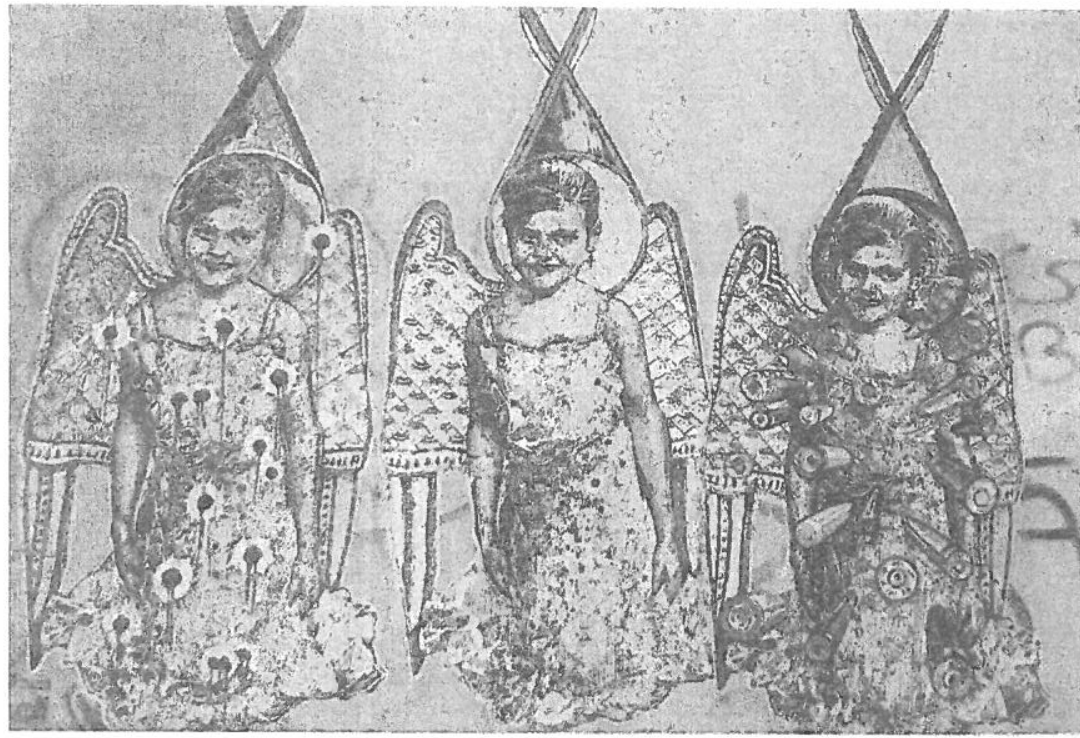

Figure 11.5 Martyr mural depicted through Christian iconography, downtown Cairo, October 2013

Photo credit: Abdo El Amir (Hamdy \& Karl, 2014)

their portrait, often adding symbols that subsume their death within a higher divine cause. For example, angel wings and phrases from Quran or Bible frame death within religious notions of martyrdom, granting them a place in heaven as having fought for the revolution. Figure 11.5 is a mural in memory of Marian, an eight-year-old girl who was shot multiple times by an unknown gunman while she was on her way to a wedding in a Coptic orthodox church (Hamdy and Karl, 2014). Even though the circumstances of her death were different from protestors who died in clashes with the police or military, her image joined those of the revolution victims in the center of revolution street art in downtown Cairo. The mural depicts the bullets in Marian's body visually referencing St. Sebastian, who is commonly depicted tied to a tree and shot with arrows in Christian iconography. The wings, hallow, the colorful bullets to the right, and the bullet marks appearing like sun flowers to the left all communicate meanings of sacrifice that give to her a holy status.

The second visual function used in commemorating civilian lives was that of social documentation of their killing incident and holding the perpetrators accountable. In some instances the painting was done in the same physical location where the person was killed so as to create an instant place reminder. Figure 11.6 shows a photograph and stenciled

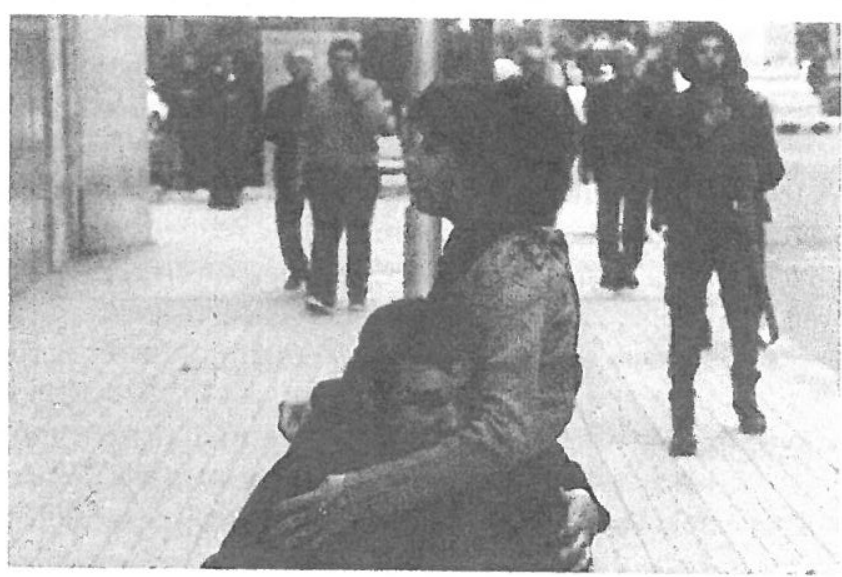

(a)

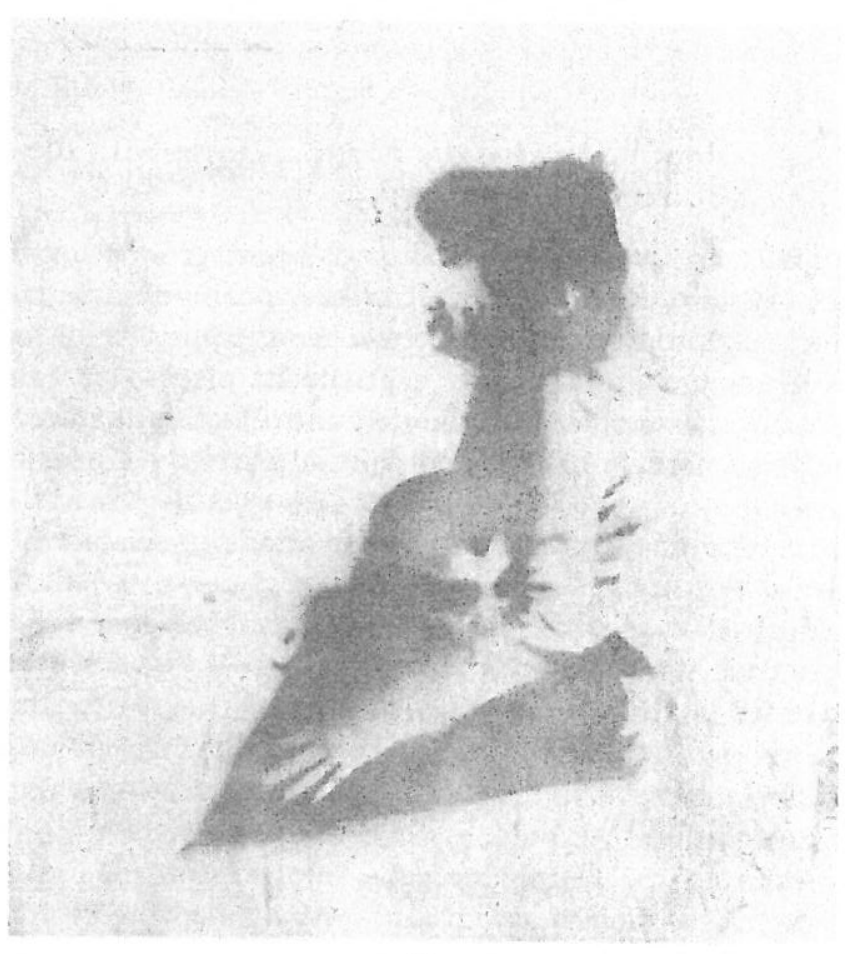

(b)

Figure 11.6 Photographs depicting (a) the shooting of activist Shaimma al-Sabbagh and (b) the stencil graffiti sprayed at the site afterward

Photo credit: Islam Osama 
image of the shooting of Socialist Popular Alliance Party activist Shaimaa al-Sabbagh during a peaceful demonstration in memory of the demonstrators killed in January 25 revolution. The photograph was taken right after she was shot, while her colleague was trying to carry her. The photo created a powerful mnemonic by capturing the iconic "about to die" moment. News photos as such document the sequencing of an event while strategically freezing it at its most visually powerful moment. "Just before death" photos create iconic representations of events for remembrance as they position the event at the "about to" moment (Zelizer, 2004).

The sprayed stencil then took this iconic visual representation and "marked" it onto the walls of the physical location where she was killed. The stencil transformed a news photo that went viral on social media and newspapers into a graffiti symbol, which in turn was diffused on city walls and social media. This continuous social life of image serves documentation and remembering into the future.

\section{Discussion: Long Live the King ... Down with the \\ King ... Long Live the King ...}

Political upheavals involve struggles of different groups for representation and visibility, mobilization of masses, positioning within dominant discourses, and a presence in collective memory. With regards to all of these functions, images have a privileged place over written discourse. Visuals reach audience in a timely and affective manner, in many instances transcending language and cultural barriers. Throughout this chapter, we have proposed that following those visuals provides one way of looking at cultural and political transformations associated with political upheavals. Through the social life of images, we observe the different functions they serve, the different social actors involved, and their circulation in context.

As illustrated in the examples, visuals are attractive resources for authoritarian regimes to stabilize their homogeneous discourse and display power over knowledge, history, and public space. But those same visual resources create risks for regimes, as they play a central role in igniting revolutions by highlighting the injustices of the system, representing the established image of authority, and giving visibility (and power) to the masses. During revolutions, a social rupture occurs that opens up a gap of opportunity to reconfigure established boundaries and create spaces of contestation and positioning. In return counterrevolutions attack those spaces and visuals through destruction, censorship, and alternative production. Following this contentious and continuous process of change tell stories of political struggles as they are occurring. Thus, the analysis shows the spaces of control and censorship, as well as of agency and resistance.

The different image functions discussed in this chapter highlight the different social and political implications they have on society.

First, the function of visibility and its illustrative example of the authority figure shows different means and forms of visibility. Traditionally regimes' exercise of power has been linked to the authority's public display of superiority and power, visibility then was about the visibility of the few in power to the masses. Surveillance technology later changed the form of visibility to be a tool of control: the masses being continuously watched by the few. The display of authority then became about the normalizing power of the gaze: the citizens internalizing the control through believing that they are always watched (Foucault, 1977). Contemporary new media is further redefining visibility, making those in power, rather than those over whom power is exercised, the primary focus of a new kind of visibility, posing "fragility" to the divine image of authority. The same tools used to promote and celebrate political leaders, are used to attack and denounce them, and previously hidden political practices and events are exposed publicly to a much wider audience across space and time (Thompson, 2005). Those new tools and access to visibility also come with their own risks of misuse, which will be further discussed below in terms of rights and duties.

New communication channels and online media are inevitably changing the power dynamics of visual culture, creating new fields of action and interaction, in which relations of power can shift quickly, dramatically, and in unpredictable ways as we saw in the example of Egypt. Under the current government in Egypt, the personification of the leader still persists from government-produced images as well as from supporters who are looking for the savior image of a leader. However, there is an inevitable effect of the spaces of contestation that the uprising has opened, which challenge the authority's ability to convey a oneway visual representation. The image of El Sisi is met with contestation by the opposition mostly online but also in street graffiti, utilizing ironic appropriation of his image and speeches, and triggering reflection on the official discourses (Wagoner, Awad, and Bresco, forthcoming). The authority still has the most power over visuals in public space, while the opposition is steered toward online media. However, the borders between these mediums are becoming more and more permeable, with images traveling between while changing shape and meaning in the process. 
Second, the mobilizing potential of images has been apparent throughout history. Flags and religious symbols have been frequently used to motivate people to go off to war and give their life for the higher cause represented by the symbol. These images are powerful group motivators because they speak primarily to our emotions rather than our reason. Through them we enter into a collective stream of feelings and ideas that bind us with others in common cause; this is why they are essential devices for protest crowds and political rallies (see Wagoner, Chapter 5). In the example of the Egyptian flag, we see how the sentiments and group boundaries have changed alongside shifting events and power dynamics. While before the revolution flags only functioned as powerful symbols of solidarity toward a common end in football matches, during the eighteen days of protest and its immediate aftermath the flag absorbed the revolutionary euphoria and became a key symbol bringing Egyptians together as equals protesting in the streets and squares. The flag was not only waved but wore on ones body and painted all over the city. Part of the military's taking back control of the country meant transforming the affective meaning of the flag. Considerable resources were spent on billboards, monuments, and celebrations that implicitly connected the flag with support for military rule. These efforts paid off such that today those waving the flag are more likely to be motivated against people protesting the government than with them.

Third, looking at how images position different actors during times of change and create contested spaces of argumentation highlights different venues of agency and social action. Looking at individuals in those contexts as reflexive agents, when confronted with various discourses they actively acquire different positions and those positions in turn influence certain actions (Harré, Lee, and Moghaddam, 2008). In the example of the Tank mural, we see that discourses and positioning do not only take place in language, but also in the images we see everyday in the streets of our cities. Images continuously present the multiple realities of a time and their social life shows the negotiation, conflict, and competition taking place between the different positions.

Of importance here are the concepts of rights and duties that are ascribed to each position and the power of different positions (Harré, Lee, and Moghaddam, 2008). While the example of the tank presents arguments between different graffiti artists in opposition and in support of the army in one physical location, the wider visual context involves positions that are widely propagated through different media platforms. On these platforms, images are continuously used to present false arguments, promote and use public ignorance, and position the producer as the source of reality and the audience as the naive and passive receiver of information. There are fabricated images of the authority figure such as in the example of Mubarak news image mentioned earlier, there are images that ignite fear such as those propagated by ISIS terrorist group, and there are images that marginalize entire groups and promote polarization in society. Those images appear to an audience as real representations of the world, and those fabrications or framing are often harder to distinguish by an audience who are less likely to spot the fake or selective representation occurring in the image process (Messaris and Abraham, 2001). In these instances, images have real moral implications in everyday life, positioning entire groups of people as "good" or "evil," "patriotic" or "traitors." They have the ability to humanize or dehumanize individuals, and to legitimize or delegitimize social struggles.

Fourth, images' function to commemorate and document personal as well as collective memories gives them a historical enduring role. Authority's monopoly over what visuals get circulated and what parts of recent history gets documented does not only shape the past but also the oriented future of the country. The whitewashing of the revolution street art and the lost lives in the uprisings, and replacing them with visuals of the "new stable Egypt" is a clear attempt of regulating the community's collective memory. And even though citizens appropriate those visuals and reconstruct their memories in an individual manner according to their own experiences and opinions, the monopoly over visual documentation has an enduring effect on the long term of enforcing certain memories and promoting the forgetting of others. Also those who have the power of representing the past in visual culture, have the power over dictating who is represented and included in the public sphere and who is excluded. Thus, the continuous interventions in the street and online to document the revolution from the perspective of activists has an important role in counteracting this effect and reaffirming presence and alternative narratives of the past. On the long and difficult pursuit of activist goals, these solidified images serve as important reminders for what one is fighting for.

\section{Conclusion: Beyond the Uprising}

Looking at the Arab uprisings and its different upheavals, trials, and failures through the lens of "hard" politics, may show that the people lost their opportunity for change. However, looking through the lens of visual culture as politics complicates this view to include the importance of the diffused everyday politics (Khatib, 2013). Revolutions are the heightened times where attention is brought to people's will; they are visible and dramatic. But it is in the "infra-politics of subordinate 
groups" that we can see the continuities of low profile forms of everyday resistance that endure in spite of the disappointments of the different revolutions (Scott, 1990). While the aspired to social changes were clearly not achieved from the revolutionary situations in Egypt, Libya, Syria, and other countries in the region, the visual culture and the actors involved in it illustrate micro processes of change in different forms of resistance to dominant powers.

The transformation of images and their implications reveals a continuous push and pull, resistance from opposition to official visual discourse and from government to alternative visual productions. It opens up the question of whether there was indeed an inevitable effect of revolutionary images in spite of the drawbacks and counterrevolutions. The different functions showed how images could be a symbolic resource for social movements as they influence the political discourse. They also showed that they could be a double edged sword; same images used to create visibility to certain groups, could be used to marginalize them, and same images used to mobilize people against injustice, could turn people numb and passive toward photos of torture and injustice.

The political potential of the different functions of images lies in the hands of the different social actors influencing the images' social lives. The examples discussed in this chapter show active producers of alternative visual culture and critical recipients of the dominant visual discourse resisting powerful ruling structures in spite of their endurance and in spite of the perceived shortcomings and failures of the uprisings. This poses moral responsibility not only on image producers but also on their receivers and gatekeepers. To the numerous images we see every day, we should question when is looking and critically appropriating an image an act of political awareness. Acts of perceiving, appropriating, refuting or destroying can all be acts of change in our visual culture. This is because the "images surrounding us do not only show how we inhabit our culture, but also how we remake it, altering the very structures by which we organize our culture" (Rogoff, 1998).

This leads us to argue that there are micro processes of social change that can be seen not only in the visual culture but also in everyday practices. From the unsuccessful revolution, groups of people have become conscious of the possibility of resistance and have learned skills for executing it. In Egypt today we do not find a completely one way, top down production of visual culture; the opposition still influences public discourse with their images, and authorities continue to respond to those images with censorship, imprisonment, and distribution of opposing images. In return, the opposition continues to use online media as well as urban spaces in spite of the risks to affirm presence in resistance to government's attempts to make the "other" invisible.

\section{REFERENCES}

Awad, S. H. (2017). Documenting a contentious memory: Symbols in the changing city space of Cairo. Culture and Psychology, 23(2), 234-254.

Awad, S. H., and Wagoner, B. (2015). Agency and creativity in the midst of social change. In C. W. Gruber, M. G. Clark, S. H. Klempe, and J. Valsiner (Eds.), Constraints of Agency: Explorations of Theory in Everyday Life (pp. 229-243). New York: Springer.

Awad, S. H., Wagoner, B., and Glaveanu, V. (2017). The (street) art of resistance. In N. Chaudhary, P. Hviid, G. Marsico, and J. Villadsen (Eds.), Resistance in Everyday Life: Constructing Cultural Experiences (pp. 161-180). New York: Springer.

Bartlett, F. C. (1924). Symbolism in folk-lore. In Proceedings of the VIIth International Congress of Psychology (pp. 278-289), Cambridge: Cambridge University Press.

(1932). Remembering: A Study in Experimental and Social Psychology. Cambridge: Cambridge University Press.

Bayat, A. (2013). Life as Politics: How Ordinary People Change the Middle East. Stanford, CA: Stanford University Press.

Billig, M. (1995). Banal Nationalism. London: Sage.

Bourdieu, P. (1979/1984). Distinction: A Social Critique of the fudgment of Taste. London: Routledge and Kegan Paul.

Connerton, P. (1989). How Societies Remember. Cambridge: Cambridge University Press.

Dewey, J. (1934/2005). Art as Experience. New York: Berkley.

Doerr, N., Mattoni, A., and Teune, S. (2014). Visuals in social movements. In D. della Porta and M. Diani (Eds.), Oxford Handbook of Social Movements (pp. 557-566). Oxford: Oxford University Press.

Farid, F. (2015). Egypt Jailed a man because he made a meme of the presiden with "Mickey Mouse" ears. Business Insider. www.businessinsider.com/.

Firth, R. (1973). Symbols: Public and Private. London: George Allen and Unwin.

Fordham, A. (2017). In a bullet-riddled mansion, a Beirut architect envisions a museum of memory. NPR, March 30. https://n.pr/2oelJol.

Foucault, M. (1977). Discipline and Punish: The Birth of the Prison (A. Sheridan, Trans.). Harmondsworth, UK: Penguin.

Giddens, A. (1985). The Nation-State and Violence. Vol. 2. Berkeley: University of California Press.

Guardian (2010). Al-Ahram newspaper defends doctored photo of Hosn Mubarak. September 17. www.theguardian.com/world/2010/sep/17/alahram-newspaper-doctored-photo-hosni-mubarak.

Halbwachs, M. (1950/1980). The Collective Memory (F. J. Ditter Jr. and V. Y. Ditter, Trans.). New York: Harper and Row.

Hamdy, B., and Karl, D. (2014). Walls of Freedom: Street Art of the Egyptian Revolution. Berlin: From Here to Fame. 
Harré, R., and Langenhove, L. (Eds.) (1998). Positioning Theory. Oxford: Blackwell.

Harré, R., Lee, N., and Moghaddam, M. F. (2008). Positioning and conflict: An introduction. In R. Harré, N. Lee, and M. F. Moghaddam (Eds.), Global Conflict Resolution through Positioning Analysis (pp. 3-20). New York: Springer.

Khatib, L. (2013). Image Politics in the Middle East: The Role of the Visual in Political Struggle. New York: I. B. Tauris.

Langer, S. (1953). Feeling and Form. New York: Charles Scribner's Sons.

(1967). Mind: An Essay on Human Feeling. Vol. 1. Baltimore: Johns Hopkins University Press.

Le Bon, G. (1895/2002). The Crowd: A Study of the Popular Mind. New York: Dover.

Lefebvre, H. (1974/1991). The Production of Space. Oxford: Basil Blackwell.

Lonchuk, M., and Rosa, A. (2011). Voices of graphic art images. In M. Märtsin, B. Wagoner, E. L. Aveling, I. Kadianaki, and L. Whittaker (Eds.), Dialogicality in Focus: Challenges to Theory, Method and Application (pp. 129-146). New York: Nova Science.

Marková, I. (2003). Dialogicality and Social Representations. Cambridge: Cambridge University Press.

Messaris, P. M., and Abraham, L. (2001). The role of image in framing news stories. In S. D. Reese, O. Gandy Jr., and A. E. Grant (Eds.), Framing Public Life: Perspectives on Media and Our Understanding of the Social World (pp. 215226). Mahwah, NJ: Lawrence Erlbaum.

Mitchell, W. J. T. (1984). What is an image? New Literary History, 15, 503-537.

(1986). Iconology: Image, Text, Ideology. Chicago: University of Chicago Press.

(1994). Picture Theory: Essays on Verbal and Visual Representation. Chicago: University of Chicago Press.

(2005). What Do Pictures Want? The Lives and Loves of Images. Chicago: University of Chicago Press.

Moscovici, S. (1984). The phenomenon of social representations. In R. M. Farr and S. Moscovici (Eds.), Social Representations (pp. 3-69). Cambridge: Cambridge University Press.

Ranciere, J. (2004). The Politics of Aesthetics: The Distribution of the Sensible (G. Rockhill, Trans.). New York: Continuum.

Rogoff, I. (1998). Studying visual culture. In N. Mirzoeff (Ed.), Visual Culture Reader (pp. 24-36). New York: Routledge.

Scott, J. C. (1990). Domination and the Arts of Resistance: Hidden Transcripts. London: Yale University Press.

Thompson, J. B. (2005). The new visibility. Theory, Culture and Society, 22(6), $31-51$.

Wagoner, B. (2017). The Constructive Mind: Bartlett's Psychology in Reconstruction. Cambridge: Cambridge University Press.

Wagoner, B., Awad, S. H., and Bresco, I. (forthcoming). The politics of representing the past: Symbolic spaces of positioning and irony. In J. Valsiner and A. Rosa (Eds.), Cambridge Handbook of Sociocultural Psychology, 2nd ed. Cambridge: Cambridge University Press.
Zelizer, B. (2004). The voice of the visual in memory. In K. R. Phillips (Ed.) Framing Public Memory (pp. 157-186). Tuscaloosa: University of Alabama. Zittoun, T., Valsiner, J., Salgado, J., Gonçalves, M. M., Vedeler, D., and Ferring, D. (2013). Human Development in the Life Course: Melodies of Living. Cambridge: Cambridge University Press. 